Methods Two cross-sectional, population-based studies were conducted by simple random sampling based on telephone interviews in 2006 and 2016-2017 respectively, including 1004 and 2,400 Chinese adults. The survey instrument used to measure the variables pertinent to the HBM, including the knowledge of the CRC, perceived susceptibility, severity, benefit, barriers, and cues to action for the CRC, has been validated by an expert panel. The changes of these factors were tested using the Pearson's chi-square test.

Results The results were shown in table 1 . The proportion having a high level of knowledge (score $\geq 2$ ) of CRC risk factors (34.0\% vs. $16.0 \%)$, and CRC screening tests (67.4\% vs. $42.4 \%)$ in 2016-2017 was higher than those in 2006 (both p<0.001). The proportion of subjects having high perceived severity score $(\geq 14)$ was greater in 2016-2017 (37.9\%) than in 2006 (29.2\%). In contrast, the perceived health/psychological and access barriers have decreased. A significantly higher proportion of subjects reported physician recommendations for CRC screening in 2016-2017 (55.3\% vs. 8.4\%). Other variables pertinent to HBM were not significant factors in the analysis.

Conclusions Based on the HBM, the knowledge of CRC risk factors; CRC screening tests; perceived severity of CRC increased, while perceived barriers to CRC testing decreased since 2006. Higher proportion received physician recommendations for CRC screening. These findings may imply the effectiveness of the government screening programme or impact of more intensive educational initiatives in the general population. This causeand-effect relationship should be examined in future studies.

\section{IDDF2018-ABS-0148 SCREENING FOR COLORECTAL CANCER IN HONG KONG: DOES THE THEORY OF PLANNED BEHAVIOUR MODEL PLAY A ROLE?}

Junjie Huang*, Ada Wang, Tiffany Pang, Maggie Chan, Sophia Leung, Colete Leung, Jason Huang, Martin Wong. JC School of Public Health and Primary Care, Faculty of Medicine, Chinese University of Hong Kong, Hong Kong SAR, China

\subsection{6/gutjnl-2018-IDDFabstracts.129}

Background Worldwide, colorectal cancer (CRC) is a leading cause of cancer mortality. Uptake of CRC screening is an important performance indicator that exerts a direct impact on programme success. We aimed to examine whether the Theory of Planned Behaviour (TPB) can predict the uptake of CRC screening that could further inform new strategies in the promotion of screening of its uptake in the general population.

Methods A population-based telephone survey was conducted in 2017. Individuals aged 61-70 years were randomly recruited. A total of 2400 eligible respondents were recruited, consisting of 1200 participants and 1200 non-participants of the government-subsidised CRC screening programme. A questionnaire validated by an expert panel of epidemiologists, gastroenterologists and public health practitioners was used to measure the attitudes towards CRC screening; normative beliefs; perceived behavioural control and intention for each participant. The association between CRC screening uptake and the factors pertinent to TPB was analysed by binary logistic regression analysis that adjusted for age, gender, education level, and household income.

Results The characteristics of respondents were shown in table 1. Multivariate regression model showed that high perceived behavioural control $\quad(\mathrm{AOR}=5.94, \quad 95 \% \quad \mathrm{CI}=4.76-7.41$,

\begin{tabular}{|c|c|c|c|c|c|c|}
\hline \multirow{3}{*}{\multicolumn{2}{|c|}{$\begin{array}{l}\text { Abstract IDDF2018-ABS-0148 T } \\
\text { respondents }\end{array}$}} & ble 1 & \multicolumn{4}{|c|}{ Characteristics of the } \\
\hline & & \multicolumn{5}{|c|}{$\mathrm{N}(\%)$} \\
\hline & & \multicolumn{2}{|c|}{$\begin{array}{c}\text { No CRC } \\
\text { screening } \\
\text { uptake }\end{array}$} & \multicolumn{2}{|c|}{$\begin{array}{l}\text { CRC screening } \\
\text { uptake }\end{array}$} & $p$-value \\
\hline \multirow[t]{3}{*}{ Age } & $61-65$ & 537 & 44.8 & 50 & 4.2 & $<0.001^{*}$ \\
\hline & $66-70$ & 663 & 55.3 & 1043 & 86.9 & $<0.001^{*}$ \\
\hline & $71-76$ & 0 & 0.0 & 93 & 7.8 & $<0.001^{*}$ \\
\hline \multirow[t]{2}{*}{ Gender } & Female & 438 & 36.5 & 524 & 43.7 & $<0.001^{*}$ \\
\hline & Male & 762 & 63.5 & 676 & 56.3 & $<0.001^{*}$ \\
\hline \multirow[t]{3}{*}{ Educational level } & $\begin{array}{l}\text { Primary education or } \\
\text { no schooling }\end{array}$ & 646 & 53.8 & 583 & 48.6 & $<0.1^{*}$ \\
\hline & Secondary education & 470 & 39.2 & 539 & 44.9 & $<0.01^{*}$ \\
\hline & $\begin{array}{l}\text { Tertiary education/ } \\
\text { others }\end{array}$ & 79 & 6.6 & 69 & 5.8 & 0.41 \\
\hline Household income & $0-10000$ & 516 & 43.0 & 672 & 56.0 & $<0.001^{*}$ \\
\hline \multirow[t]{3}{*}{ (HK\$) } & $10001-20000$ & 303 & 25.3 & 204 & 17.0 & $<0.001^{*}$ \\
\hline & $>20000$ & 193 & 16.1 & 145 & 12.1 & $<0.01^{*}$ \\
\hline & Refuse to answer & 188 & 15.7 & 179 & 14.9 & 0.61 \\
\hline \multirow[t]{2}{*}{ Normative beliefs } & Low (score: 0-2.9) & 1079 & 89.9 & 932 & 77.7 & $<0.001^{*}$ \\
\hline & High (score: 3-4) & 121 & 10.1 & 268 & 22.3 & $<0.001^{*}$ \\
\hline Perceived & Low (score: $0-2.9$ ) & 922 & 76.8 & 359 & 29.9 & $<0.001^{*}$ \\
\hline behavioural control & High (score: 3-4) & 278 & 23.2 & 841 & 70.1 & $<0.001^{*}$ \\
\hline \multirow[t]{2}{*}{ Intention } & Low (score: 0-2) & 508 & 42.3 & 183 & 15.3 & $<0.001^{*}$ \\
\hline & High (score: 3-4) & 680 & 56.7 & 1017 & 84.8 & $<0.001^{*}$ \\
\hline
\end{tabular}

Abstract IDDF2018-ABS-0148 Table 2 Results of binary logistic regression for predicting the uptake of CRC screening

\begin{tabular}{|c|c|c|c|}
\hline & & \multicolumn{2}{|c|}{ Multivariate analysis } \\
\hline & & $\begin{array}{l}\text { Adjusted OR } \\
\qquad(95 \% \mathrm{Cl})\end{array}$ & $\mathrm{p}$-value \\
\hline Age & Age & $1.40(1.33-1.46)$ & $<0.001^{*}$ \\
\hline \multirow[t]{2}{*}{ Gender } & Male & Reference & \\
\hline & Female & $\begin{array}{c}0.78(0.63- \\
0.970)\end{array}$ & $<0.1^{*}$ \\
\hline \multirow[t]{3}{*}{ Educational level } & $\begin{array}{l}\text { Primary education or no } \\
\text { schooling }\end{array}$ & Reference & \\
\hline & Secondary education & $1.34(1.08-1.68)$ & $<0.01^{*}$ \\
\hline & Tertiary education/others & $0.78(0.51-1.18)$ & 0.238 \\
\hline \multirow[t]{4}{*}{ Household income (HK\$) } & $0-10000$ & Reference & \\
\hline & $10001-20000$ & $0.91(0.69-1.19)$ & 0.490 \\
\hline & 20000-above & $0.84(0.61-1.14)$ & 0.257 \\
\hline & Refuse to answer & $1.54(1.13-2.10)$ & $<0.01^{*}$ \\
\hline Positive attitude towards CRC & Direct measurement & $1.26(1.10-1.45)$ & $<0.001^{*}$ \\
\hline screening & Indirect measurement & $1.23(1.08-1.41)$ & $<0.01^{*}$ \\
\hline \multirow[t]{2}{*}{ Normative beliefs } & Low (score: 0-2.9) & Reference & \\
\hline & High (score: 3-4) & $1.04(0.78-1.40)$ & 0.775 \\
\hline \multirow[t]{2}{*}{ Perceived behavioural control } & Low (score: 0-2.9) & Reference & \\
\hline & High (score: 3-4) & $5.94(4.76-7.41)$ & $<0.001^{*}$ \\
\hline \multirow[t]{2}{*}{ Intention for CRC screening } & Low (score: 0-2) & Reference & \\
\hline & High (score: 3-4) & $3.03(2.39-3.83)$ & $<0.001^{*}$ \\
\hline
\end{tabular}

$\mathrm{p}<0.001$ ), high intention for $\mathrm{CRC}$ screening $(\mathrm{AOR}=3.03$, $95 \% \mathrm{CI}=2.39-3.83, \mathrm{p}<0.001$ ) and positive attitude towards 
CRC screening (direct measurement: adjusted odds ratio $(\mathrm{AOR})=1.26, \quad 95 \%$ confidence interval $(\mathrm{CI})=1.10-1.45$, $\mathrm{p}<0.001$; for indirect measurement: $\mathrm{AOR}=1.23$, $95 \%$ $\mathrm{CI}=1.08-1.41, \quad \mathrm{p}<0.01)$ were significantly associated with CRC screening uptake (table 2).

Conclusions The variables pertinent to the TPB could successfully predict the uptake of CRC screening. Promotion of CRC screening based on enhancing perceived behavioural control as well as behavioural intention could be effective in increasing screening uptake. Further studies are needed to establish a cause-and-effect relationship between these variables and uptake, as well as to evaluate the cost-effectiveness of such interventions.

\section{IDDF2018-ABS-0149 MANIPULATION OF GUT MICROBIOTA IN IN VITRO MODEL OF COLORECTAL CANCER: POSITIVE EFFECTS OF LACTOBACILLUS RHAMNOSUS AGAINST FUSOBACTERIUM NUCLEATUM}

Tan Wei Jian*, Norfilza Mohd Mokhtar, Raja Affendi Raja Ali, Wong Kon Ken. National University of Malaysia, Malaysia

\subsection{6/gutjnl-2018-IDDFabstracts. 130}

Background Colorectal cancer (CRC), a leading cause of morbidity and mortality worldwide, is affecting more than 1.36 million people every year. It is a well-known multifactorial disease, and the aetiology is a complex interaction between genetic, lifestyle and environmental factors. However, there has been a general consensus exists that the composition of the human intestinal microbiota is linked to health status. They mainly play a role in modulating normal gut immune function, and most of them are largely beneficial to human. Fusobacterium nucleatum is an anaerobic oral commensal and a periodontal pathogen associated with a wide spectrum of human diseases. Findings from human and animal models have revealed that fusobacterium nucleatum plays a role in colorectal carcinogenesis by suppressing the immune response of the hosts to tumour. The aim of the present study is to determine the role of a probiotic strain in competing with a selected colorectal cancer pathogen.

Methods Thus, lactobacillus rhamnosus was investigated in vitro to examine its ability to protect, displace and compete with fusobacterium nucleatum. In this study, three different types of assay (protection assay, displacement assay and competitive assay) were performed using SW480, a colorectal cancer cell line as a host cell. Cell proliferation assay was applied to determine the proliferation rate of the cells by measuring the cell metabolic activity.

Results In a competitive assay, lactobacillus rhamnosus showed greater ability of adherence to host cells than fusobacterium nucleatum with a ratio of 1400:1. Lactobacillus rhamnosus could significantly decrease the proliferation rate induced by fusobacterium nucleatum in protection assay $(\mathrm{p}<0.001)$. In addition, the proliferation rate induced by fusobacterium nucleatum was also decreased up to $48.6 \%$ in displacement assay by lactobacillus rhamnosus.

Conclusions This finding may suggest that lactobacillus rhamnosus could help limiting cell proliferation of the cancerous cells in response to pathogens. In conclusion, lactobacillus rhamnosus has a positive impact in reducing the risk of colorectal cancer and possibly an option for preventive.

\section{IDDF2018-ABS-0152 THE PREOPERATIVE CEA CAN BE AN INDEPENDENT PREDICTIVE FACTOR FOR COLORECTAL CANCER PATIENTS AFTER CURATIVE RESECTION IN LONG-TERM OUTCOME}

Shu Huan Huang*, Wen Sy Tsai, Jeng Fu You, Yu Jen Hsu, Yih Jong Chern, Hsin Yuan Hung, Chien Yuh Yeh, Pao Shiu Hsieh, Sum Fu Chiang, Cheng Chou Lai, Reiping Tang, Jinn Shiun Chen, Jy Ming Chiang. Linkou Chang Gung Memorial Hospital, Taiwan

\subsection{6/gutjnl-2018-IDDFabstracts. 131}

Background The preoperative carcinoembryonic antigen (CEA) level as a prognostic factor of colorectal cancer (CRC) has been in debate.

Methods A consecutive case series were collected from our database of CRC from 1995 to 2010. Clinicopathological factors were matched by propensity score methods with calliper width of 0.05 and a 1:4 ratio. Long-term overall survival (OS) and disease-specific survival (DSS) were analysed and compared between 3 different serum CEA levels.

Results A total number of 9634 patients were included initially. After exclusion and matching, a number of 6099 cases were matched by propensity score matching methods with median follow-up period 86 months.

The survival analysis showed poor OS in elevated serum CEA groups than normal CEA level (5 year survival rate: $75 \%$ vs. $66 \%$ vs. $61 \%$ ) and was also presented in both subgroups divided by lymph node (LN) stage (LN positive: $69 \%$ vs. $56 \%$ vs. $50 \%$, LN negative: $83 \%$ vs. $77 \%$ vs. $72 \%$ ) but not between elevated groups. In contrast, DSS showed significantly poor outcome between each group and was proportional to serum CEA elevation (5 year survival rate: $83 \%$ vs. $76 \%$ vs. $69 \%, \mathrm{p}<0.03$ between each group) and in LN negative subgroup (5 year survival rate: $92 \%$ vs. $87 \%$ vs. $82 \%$ ). In contrast, the elevated CEA in LN positive subgroup showed poor DSS (5 year survival rate: $75 \%$ vs. $65 \%$ vs. $56 \%$ ) than non-elevated group $(\mathrm{p}<0.001)$ but not between elevated groups $(\mathrm{p}=0.064)$.

In multivariate Cox regression model after adjusted with TNM stage, smoking, DM, renal insufficiency, liver cirrhosis and other factors, elevated CEA showed higher risk in DSS (5 to $10 \mathrm{ng} / \mathrm{ml} \mathrm{HR}=1.540,>10 \mathrm{ng} / \mathrm{ml} \mathrm{HR}=1.910$, both $\mathrm{p}<0.001)$. Conclusions Elevated preoperative serum CEA can be an independent prognostic factor for stage I to III CRC patients after curative resection with poor long-term overall and oncological outcome.

\section{IDDF2018-ABS-0158 ENDOSCOPIC PREDICTORS OF THE DEPTH INFILTRATION OF COLORECTAL LATERALLY SPREADING TUMOURS}

Zilin Kan, Peng Jin. PLA Army General Hospital, China

10.1136/gutjnl-2018-IDDFabstracts.132 